\title{
Simulasi Perencanaan Ruang Henti Khusus pada Simpang Bersinyal Jalan Dr.Ir.H. Soekarno-Jalan Kertajaya Indah Surabaya Ditinjau dari Nilai Tundaan
}

\author{
Youngky Riantara Putra dan Ervina Ahyudanari \\ Jl. Arief Rahman Hakim, Surabaya 60111 Indonesia \\ e-mail:ervina@ce.its.ac.id
}

Jurusan Teknik Sipil, Fakultas Teknik Sipil dan Perencanaan, Institut Teknologi Sepuluh Nopember (ITS)

\begin{abstract}
Abstrak - Salah satu upaya yang telah dikaji dalam mengatasi masalah kemacetan di kota-kota besar di Indonesia adalah dengan penerapan Ruang Henti Khusus (RHK) untuk sepeda motor pada persimpangan bersinyal. Surabaya merupakan kota kedua terbesar di Indonesia yang sering mengalami kemacetan terutama pada persimpangan bersinyal. Oleh karena itu perlu dicari kinerja dari persimpangan bersinyal pada lokasi studi yang ditentukan baik sebelum maupun sesudah diterapkan RHK. Tugas Akhir ini melakukan analisis kinerja RHK pada simpang bersinyal Jalan Dr. Ir. H. Soekarno - Jalan Kertajaya Indah ditinjau dari nilai tundaan. Adapun metode yang digunakan menggunakan proses simulasi yang terdiri dari simulasi kedatangan, simulasi antrian, dan simulasi pelepasan. Parameter yang digunakan menggunakan acuan waktu, dimana hasil dari sebelum dan sesudah diterapkan RHK dibandingkan dengan pola grafik yang mengacu pada nilai durasi lepas dan durasi tunggu. Makin besar nilai dua durasi tersebut maka makin besar nilai tundaan yang terjadi pada antrian kendaraan. Hasil yang diperoleh untuk dimensi dan tipe RHK yang diterapkan pada lokasi studi adalah RHK tipe kotak dengan panjang 12 meter. Hasil kinerja yang diperoleh muncul tiga kondisi yang mana kondisi ini menggambarkan pola grafik yang berbeda tergantung dari perubahan komposisi antrian akibat adanya penerapan RHK.
\end{abstract}

Kata Kunci : Ruang Henti Khusus, Durasi Lepas, Durasi Tunggu, Simulasi. Kinerja Persimpangan.

\section{PENDAHULUAN}

K OTA Surabaya adalah ibu kota Provinsi Jawa Timur sekaligus menjadi kota metropolitan terbesar kedua di Indonesia. Pertambahan jumlah kendaraan pribadi, terutama sepeda motor, menambah kemacetan pada ruas jalan [1]. Penumpukan kendaraan yang tidak teratur mengakibatkan penguraian kepadatan antrian kendaraan pada persimpangan menjadi lama. Di Indonesia upaya pemerintah dalam mengatasi masalah kemacetan terutama pada persimpangan bersinyal adalah adanya pemberlakuan Ruang Henti Khusus (RHK). RHK memisahkan antara antrian sepeda motor dengan kendaraan roda empat pada persimpangan bersinyal [2]. RHK sendiri merupakan modifikasi dari Advanced Stop Lines (ASLs) yang diterapkan di Inggris dengan tujuan memisahkan antrian pengendara sepeda dengan mobil untuk keselamatan pengendara sepeda [3]. Melihat kondisi pada persimpangan bersinyal akibat pengaruh penumpukan arus yang tidak teratur [4] dinilai perlu dilakukan analisis lebih jauh untuk diterapkannya RHK di Indonesia. Analisis ini mengarah kepada pengaruh pemberlakuan RHK terhadap proses penguraian penumpukan arus pada persimpangan bersinyal ditinjau dari besarnya nilai tundaan yang terjadi [5]. Nilai tundaan ini akan diperoleh dari proses simulasi kondisi eksisting dan simulasi hasil perencanaan RHK [6]. Analisis yang akan dilakukan mengambil kondisi arus eksisting pada persimpangan Jalan Dr. Ir. H. Soekarno - Jalan Kertajaya Indah.

\section{METODOLOGI}

\section{A. Alur Pemikiran}

Proses simulasi dilakukan berdasarkan karakteristik kondisi arus eksisting di Surabaya. Proses simulasi ini terdiri dari simulasi nyala merah untuk waktu kedatangan kendaraan, simulasi blok antrian, dan simulasi nyala hijau untuk pelepasan antrian kendaraan. Dalam pelaksanaan studi ini dibuat suatu metodologi untuk memudahkan dan mengarahkan untuk mencapai tujuan studi. Dimana tujuan dalam studi ini adalah mendapatkan kinerja persimpangan [7] pada pendekat studi dengan kondisi sebelum dan sesudah diterapkan RHK.

\section{B. Pengumpulan Data}

Pada tahap pengumpulan data terdiri dari pengumpulan data sekunder dan pengumpulan data primer.

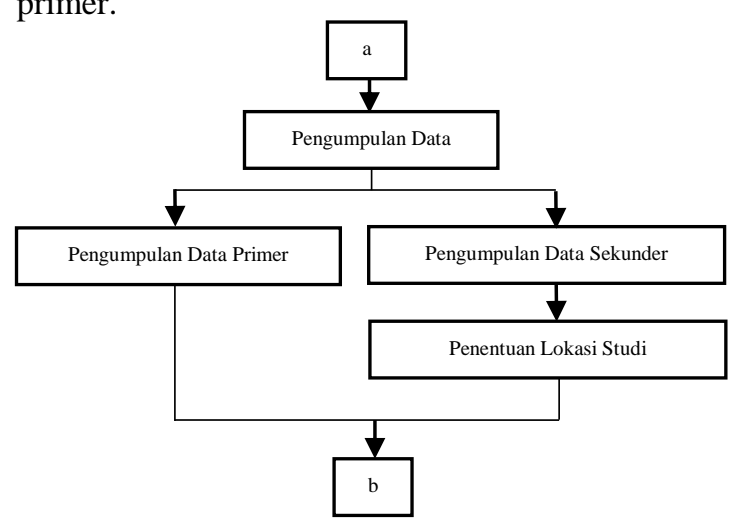

Gambar 1. Diagram Alir Pengumpulan Data

a. Pengumpulan data sekunder 
Pengumpulan data sekunder dilakukan untuk memperoleh gambar kondisi eksisting persimpangan Jalan Dr. Ir. H. Soekarno - Jalan Kertajaya Indah. Gambar 2. menunjukkan geometri simpang Jalan Dr. Ir. H. Soekarno - Jalan Kertajaya Indah.

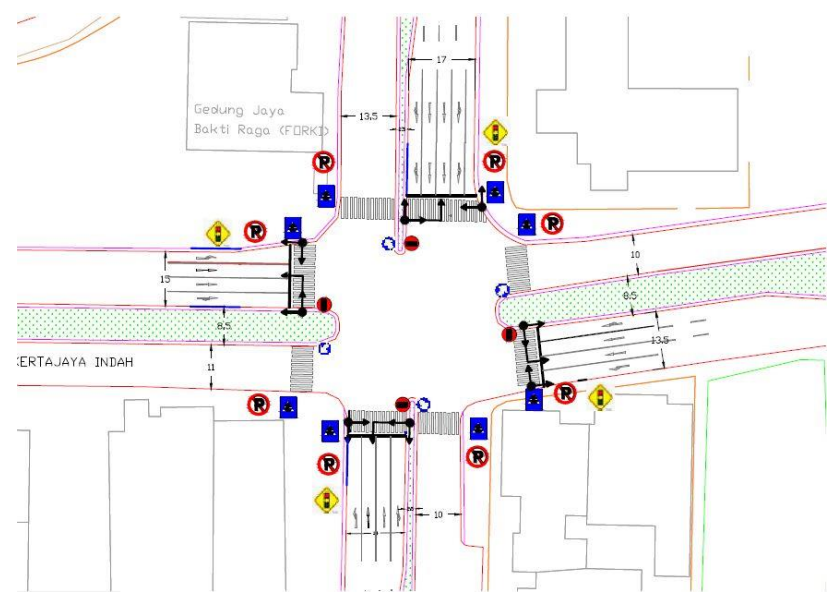

Gambar 2. Kondisi Eksisting Simpang

\section{b. Penentuan lokasi studi}

Berdasarkan rekap hasil data sekunder dari Dinas Perhubungan Surabaya untuk keempat pendekat, maka didapatkan rata-rata penumpukan sepeda motor per fase (unit) sebagai berikut :

1. Penumpukan sisi utara $=110,10 \sim 111$ unit.

2. Penumpukan sisi barat $=79,60 \sim 80$ unit.

3. Penumpukan sisi selatan $=89,17 \sim 90$ unit.

4. Penumpukan sisi timur $=66,53 \sim 67$ unit.

Berdasarkan hasil rata - rata penumpukan penumpukan sepeda motor per fase, maka dipilih pendekat sisi utara sebagai lokasi studi karena memiliki nilai terbesar yaitu 111 unit per fase.

\section{c. Pengumpulan data primer}

Data primer yang dijadikan entri untuk simulasi adalah data pergerakan lalu lintas di lokasi studi hasil pengumpulan data yang ditunjukkan pada gambar 3 .

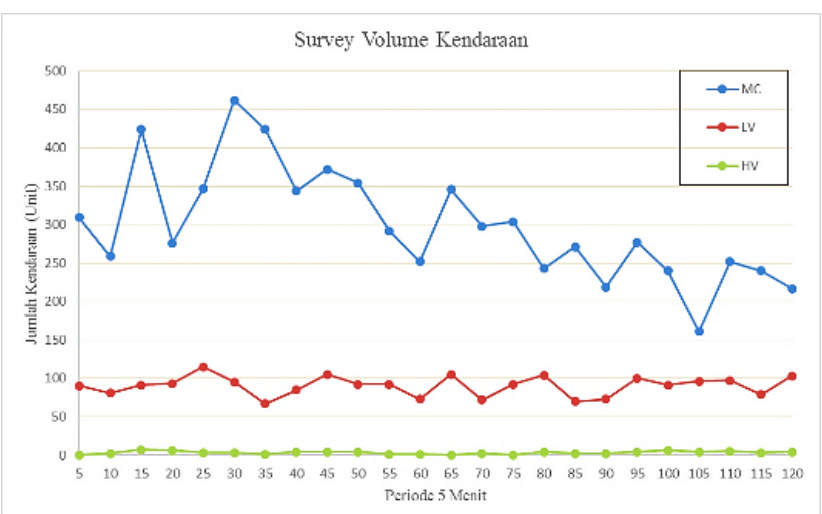

Gambar 3. Grafik Volume Kendaraan 07.15-09.15 WIB

\section{Proses Simulasi}

Proses simulasi terdiri dari simulasi kedatangan pada nyala merah, simulasi blok antrian, dan simulasi pelepasan pada nyala hijau. Dalam proses simulasi ini tingkat kedatangan kendaraan yang diperoleh dari data primer menjadi entri dalam proses simulasi.

\section{Analisis Kinerja Simpang}

Analisis yang dilakukan dengan membandingkan hasil kinerja pendekat studi sebelum dan sesudah diterapkan RHK. Dalam analisis ini, variabel pembanding kinerja simpang adalah durasi lepas maksimum dan durasi tunggu maksimum kendaraan.

\section{HASIL DAN PEMBAHASAN}

\section{A. Analisis Data dan Simulasi Kondisi Eksisting}

\section{a. Penentuan jenis distribusi data}

Penentuan jenis distribusi data terdiri dari penentuan jenis distribusi data untuk waktu antar kedatangan sepeda motor dan waktu antar kedatangan mobil. Penentuan jenis distribusi didapatkan dari pengambilan 100 sampel untuk waktu antar kedatangan sepeda motor dan 50 sampel untuk waktu antar kedatangan mobil. Sampel tersebut kemudian dicari jenis distribusinya menggunakan program bantu statistik. Didapatkan jenis distribusi untuk waktu antar kedatangan sepeda motor berdistribusi Gamma dengan nilai parameter $\alpha=0,5232 ; \beta=2,6950$; dan $\gamma=0$ dan jenis distribusi untuk waktu antar kedatangan mobil berdistribusi Exponential dengan nilai parameter $\lambda=$ 0,$1730 ;$ dan $\gamma=1,0000$

\section{b. Uji validasi distribusi data}

Hasil penentuan distribusi data dilakukan uji validasi. Uji validitas distribusi data berikut terdiri dari uji untuk waktu antar kedatangan sepeda motor dan waktu antar kedatangan mobil.

Tabel 1.

Hasil Uji Distribusi Waktu Antar Kedatangan Sepeda Motor

\begin{tabular}{|l|l|}
\hline Chi-Squared \\
\hline P-Value & 0.06444 \\
\hline$\alpha$ & 0.01 \\
\hline \multirow{2}{*}{ Kesimpulan } & P-value $>\alpha$ \\
\cline { 2 - 2 } & $0.06444>0.01($ Gagal Tolak H0) \\
\hline
\end{tabular}

Kesimpulan :

Karena P-value $>\alpha(0,0644>0,01)$ maka distribusi waktu antar kedatangan sepeda motor berdistribusi Gamma.

Tabel 2.

Hasil Uji Distribusi Waktu Antar Kedatangan Mobil

\begin{tabular}{|l|l|}
\hline Chi-Squared & 0.68695 \\
\hline P-Value & 0.01 \\
\hline$\alpha$ & $P$-value $>\alpha$ \\
\cline { 2 - 2 } Kesimpulan & $0.68695>0.01($ Gagal Tolak $\mathrm{H} 0)$ \\
\hline
\end{tabular}

Kesimpulan :

Karena P-value $>\alpha(0,68695>0,01)$ maka distribusi waktu antar kedatangan mobil berdistribusi Exponential. 


\section{c. Membangkitkan nilai acak}

Hasil distribusi waktu antat kedatangan sepeda motor dan mobil digunakan untuk membangkitkan nilai acak. Nilai acak ini digunakan untuk menentukan kedatangan kendaraan pada persimpangan pendekat studi dalam proses simulasi. Hasil bangkitan nilai acak dapat dilihat pada tabel 3.

Tabel 3.

Hasil Bangkitan Nilai Acak

\begin{tabular}{|c|c|c|c|}
\hline \multicolumn{4}{|c|}{ Bangkitan Nilai Acak } \\
\hline \multicolumn{2}{|c|}{ Sepeda Motor } & \multicolumn{2}{c|}{ Mobil } \\
\hline $\mathbf{V}$ & Rand & V & Rand \\
\hline $\mathbf{1}$ & 0.3055 & $\mathbf{1}$ & 4.6341 \\
\hline $\mathbf{2}$ & 0.4609 & $\mathbf{2}$ & 4.0246 \\
\hline $\mathbf{3}$ & 0.5834 & $\mathbf{3}$ & 2.6169 \\
\hline $\mathbf{4}$ & 0.0788 & $\mathbf{4}$ & 10.3186 \\
\hline $\mathbf{5}$ & 0.0014 & $\mathbf{5}$ & 7.1287 \\
\hline
\end{tabular}

\section{d. Simulasi kondisi eksisting}

Simulasi dilakukan sebanyak 15 kali untuk melihat kinerja persimpangan pendekat studi sebelum dan sesudah diterapkan RHK. Proses simulasi meliputi simulasi kedatangan pada nyala merah, simulasi blok antrian kendaraan, dan simulasi pelepasan kendaraan pada nyala hijau.

- Simulasi kedatangan pada nyala merah.

Hasil bangkitan nilai acak yang telah didapatkan digabungkan satu proses simulasi kedatangan kendaraan pada nyala merah. Proses simulasi kedatangan pada nyala merah dapat dilihat pada tabel 4 dan 5 .

Tabel 4.

Simulasi 1 Kedatangan Sepeda Motor

\begin{tabular}{|c|c|c|c|c|}
\hline \multicolumn{5}{|c|}{ Sim 1 } \\
\hline Rand & V & IAT & ToA & TiL \\
\hline 0.3055 & $\mathbf{1}$ & 0.31 & 0.31 & 179.69 \\
\hline 0.4609 & $\mathbf{2}$ & 0.47 & 0.78 & 179.22 \\
\hline 0.5834 & $\mathbf{3}$ & 0.59 & 1.37 & 178.63 \\
\hline 0.0788 & $\mathbf{4}$ & 0.08 & 1.45 & 178.55 \\
\hline 0.5415 & $\mathbf{1 6 1}$ & 0.55 & 173.88 & 6.12 \\
\hline 0.3157 & $\mathbf{1 6 2}$ & 0.32 & 174.2 & 5.8 \\
\hline 6.3249 & $\mathbf{1 6 3}$ & 6.33 & 180.53 & -0.53 \\
\hline
\end{tabular}

Tabel 5.

Simulasi 1 Kedatangan Mobil

\begin{tabular}{|c|c|c|c|c|}
\hline \multicolumn{5}{|c|}{ Sim 1 } \\
\hline Rand & V & IAT & ToA & TiL \\
\hline 4.6341 & $\mathbf{1}$ & 4.64 & 4.64 & 175.36 \\
\hline 4.0246 & $\mathbf{2}$ & 4.03 & 8.67 & 171.33 \\
\hline 2.6169 & $\mathbf{3}$ & 2.62 & 11.29 & 168.71 \\
\hline 10.3186 & $\mathbf{4}$ & 10.32 & 21.61 & 158.39 \\
\hline 3.9285 & $\mathbf{2 4}$ & 3.93 & 168.64 & 11.36 \\
\hline 5.2444 & $\mathbf{2 5}$ & 5.25 & 173.89 & 6.11 \\
\hline 6.8766 & $\mathbf{2 6}$ & 6.88 & 180.77 & -0.77 \\
\hline
\end{tabular}

Dari kedua tabel diatas, maka dapat diketahui jumlah kendaraan berhenti pada tiap proses simulasi.

- Simulasi blok antrian kendaraan.

Blok antrian didesain menyesuaikan kondisi di lapangan yang didapatkan dari hasil perekaman video.

1. Lebar satu blok antrian diambil sama dengan lebar lajur yaitu sebesar 3,5 meter.

2. Panjang satu blok antrian diambil setara dengan panjang satu mobil yaitu sebesar 4 meter.

3. Penempatan kendaraan di dalam blok antrian dibagi menjadi dua jenis blok. Blok Tipe 1 yaitu blok yang terdiri dari satu mobil dan dua sepeda motor. Blok Tipe 2 yaitu blok yang terdiri dari delapan sepeda motor [8]. Penempatan kendaraan disajikan pada gambar berikut.

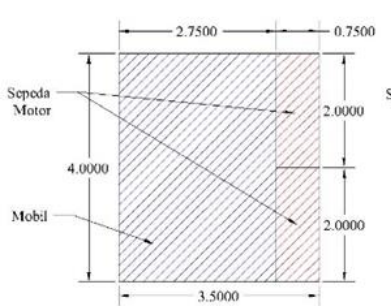

(a)

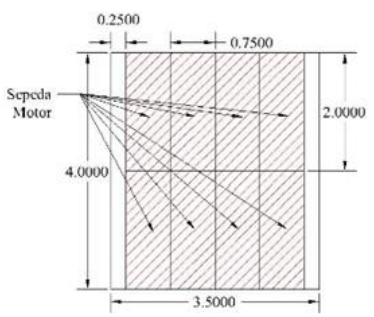

(b)
Gambar 7. Blok Tipe 1 (a); Blok Tipe 2 (b)

- Simulasi pelepasan kendaraan pada nyala hijau.

Acuan yang digunakan blok antrian dalam proses pelepasan ini menggunakan hasil survey waktu tempuh dan waktu reaksi kendaraan yang ada di lapangan.

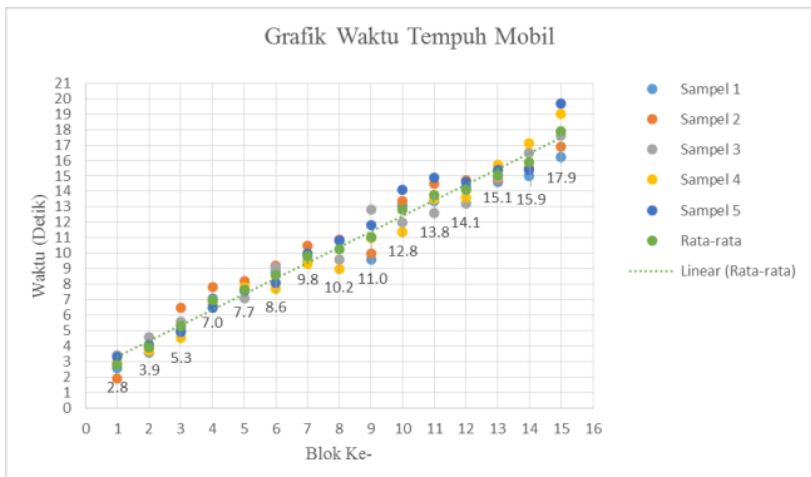

Gambar 4. Grafik Waktu Tempuh Mobil

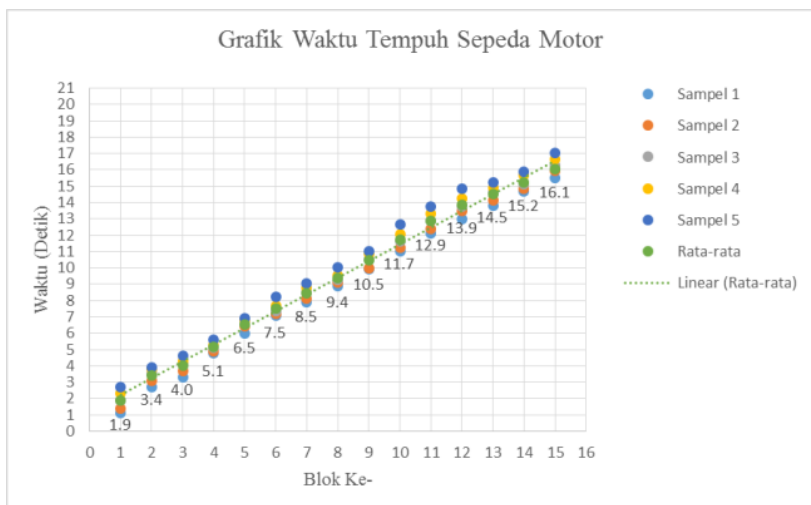

Gambar 5. Grafik Waktu Tempuh Sepeda Motor

Tabel 6.

Waktu Start Kendaraan 


\begin{tabular}{|c|c|c|c|c|c|c|}
\hline \multirow{2}{*}{ Waktu Start } & \multicolumn{7}{|c|}{ Sampel ke - } \\
\cline { 2 - 7 } & $\mathbf{1}$ & $\mathbf{2}$ & $\mathbf{3}$ & $\mathbf{4}$ & $\mathbf{5}$ & Rata-rata \\
\hline Mobil & 2.9 & 3.4 & 3.7 & 2.4 & 3.1 & 3.1 \\
\hline Motor & 1.1 & 0.9 & 1.2 & 1.4 & 1.5 & 1.2 \\
\hline
\end{tabular}

Tabel 7.

Waktu Reaksi Blok Antrian

\begin{tabular}{|c|c|c|c|c|c|c|c|}
\hline \multicolumn{7}{|c|}{ Waktu Reaksi } & \multicolumn{5}{|c|}{ Sampel Ke- } & \multirow{2}{*}{ Rata-rata } \\
\hline Depan & Belakang & $\mathbf{1}$ & $\mathbf{2}$ & $\mathbf{3}$ & $\mathbf{4}$ & $\mathbf{5}$ & \\
\hline Tipe 1 & Tipe 1 & 1.5 & 1.6 & 1.2 & 1.5 & 1.3 & 1.4 \\
\hline Tipe 2 & Tipe 2 & 0.9 & 0.7 & 0.6 & 0.8 & 0.7 & 0.7 \\
\hline Tipe 1 & Tipe 2 & 1 & 0.7 & 1.1 & 0.7 & 1.1 & 0.9 \\
\hline Tipe 2 & Tipe 1 & 1.1 & 0.9 & 1 & 0.9 & 1 & 1.0 \\
\hline
\end{tabular}

Setelah didapatkan waktu tempuh dan waktu reaksi, selanjutnya dilakukan proses simulasi pelepasan nyala hijau.

\section{B. Perencanaan dan Simulasi Ruang Henti Khusus}

Perencanaan RHK menggunakan pedoman Perencanaan Teknis Ruang Henti Khusus (RHK) Sepeda Motor Pada Simpang Bersinyal di Kawasan Perkotaan Rancangan 2 disusun oleh Kementerian Pekerjaan Umum. Pedoman ini menjelaskan ketentuan dan prosedur tentang tata cara perancangan RHK.

\section{a. Persyaratan kebutuhan RHK}

Sesuai dengan pedoman Perencanaan Teknis Ruang Henti Khusus (RHK), maka terdapat persyaratan dalam menentukan jenis dan dimensi RHK. Persyaratan tersebut terdiri dari persyaratan geometrik persimpangan dan persyaratan kondisi lalu lintas.

\section{b. Perancangan teknis desain RHK}

Pada tahap perancangan teknis desain RHK terdiri dari penggunaan asumsi sepeda motor rencana, perancangan tipe RHK, dan perancangan dimensi area RHK. Didapatkan RHK Tipe Kotak dengan panjang sebesar 12 meter.

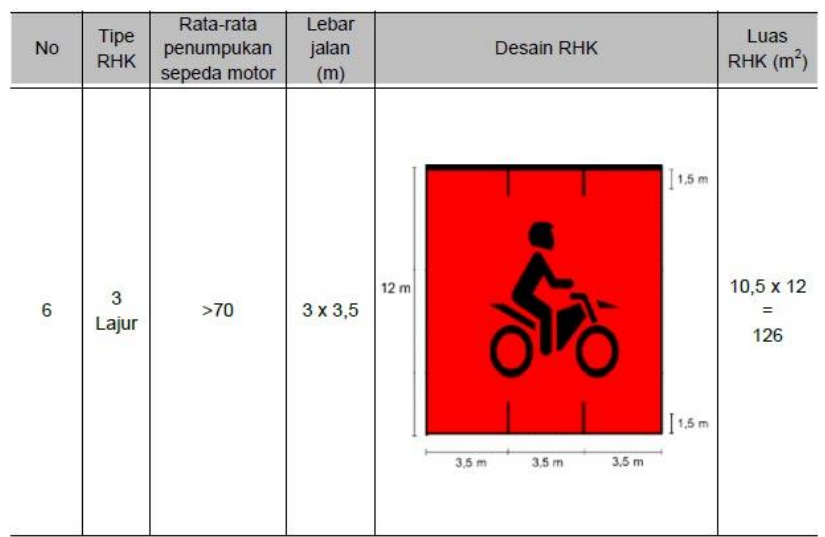

Gambar 6. Tipe dan Dimensi RHK Berdasarkan Pedoman Perancangan Teknis RHK.

\section{c. Simulasi Kondisi RHK}

Proses simulasi kondisi RHK dilakukan dengan parameter dan kondisi lalu lintas yang sama seperti simulasi kondisi eksisting.

\section{d. Analisis kinerja simulasi kondisi eksisting dan RHK}

Dari dua hasil grafik terlihat pada grafik kinerja kondisi RHK cenderung berada di bawah grafik kinerja kondisi eksisting. Hal ini menunjukkan bahwa pada kinerja kondisi RHK memberikan nilai durasi lepas dan nilai durasi tunggu yang lebih kecil dari pada nilai pada kondisi eksisting. Sehingga kondisi RHK memberikan dampak pada nilai tundaan yang lebih kecil dibandingkan eksisting.

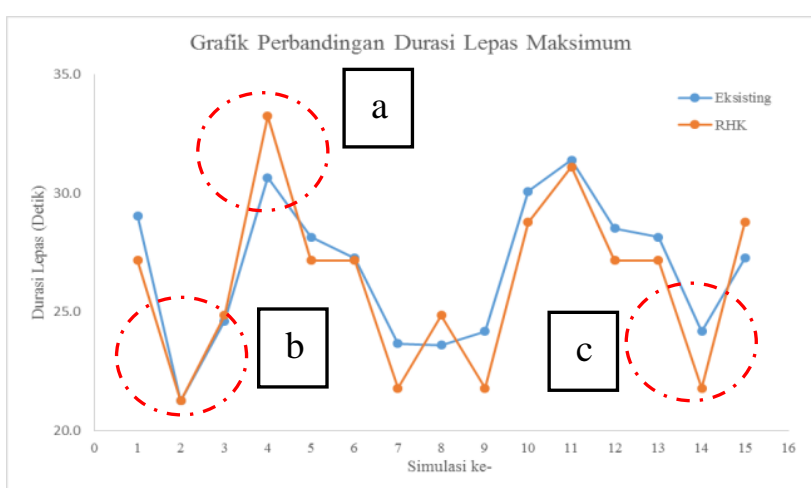

Gambar 7. Grafik Perbandingan Durasi Lepas Maksimum

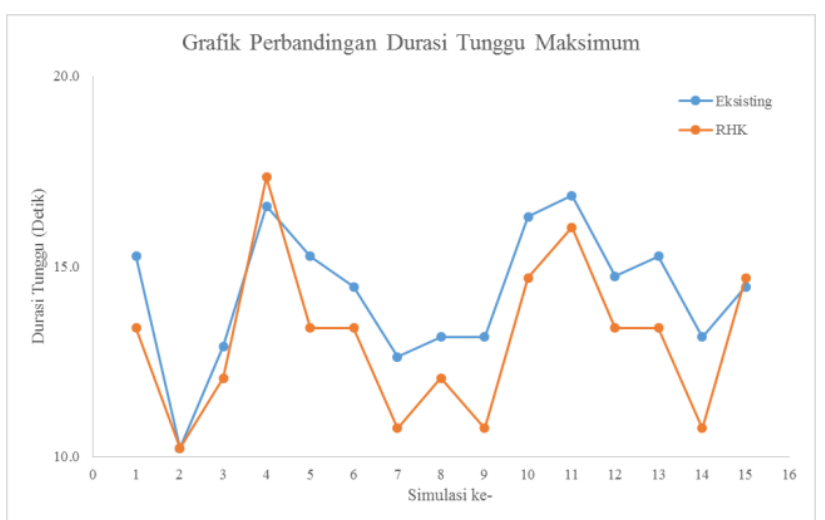

Gambar 8. Grafik Perbandingan Durasi Tunggu Maksimum

Didapatkan tiga kondisi grafik yang kemudian akan dibahas detdetail mengenai perbedaan kinerja RHK dan eksisting.

- Kondisi a

Kondisi a adalah kondisi dimana penerapan RHK memberikan dampak pada nilai durasi lepas maksimum yang lebih besar terhadap kondisi eksisting.

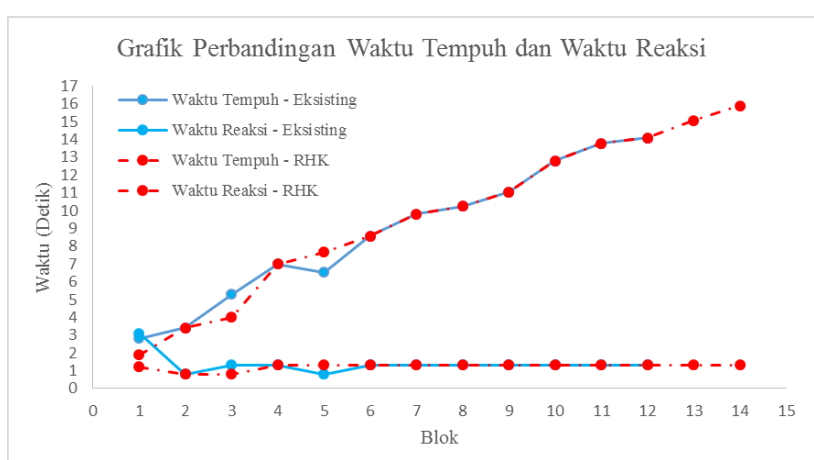

Gambar 9. Grafik Perbandingan Simulasi 4 


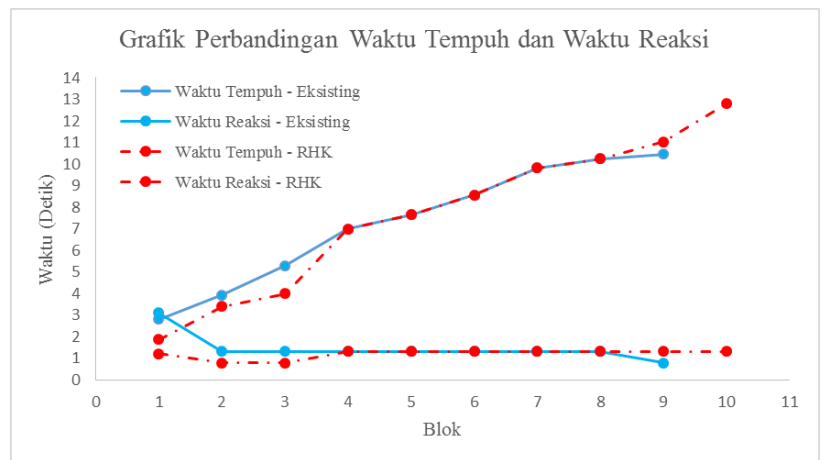

Gambar 10. Grafik Perbandingan Simulasi 8

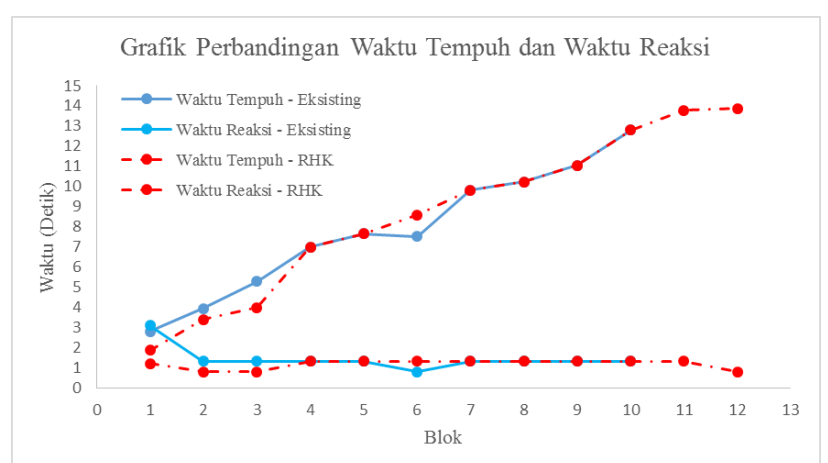

Gambar 11. Grafik Perbandingan Simulasi 15

Berdasarkan tiga grafik yang disajikan penerapan RHK mampu memberikan dampak dalam mengurangi nilai durasi lepas dan durasi tunggu pada tiga blok pertama dimana grafik kondisi RHK berada di bawah grafik kondisi eksisting. Namun, pada grafik kondisi RHK mengalami kenaikan yang diikuti dengan adanya penambahan blok.

\section{- Kondisi b}

Kondisi b adalah kondisi dimana penerapan RHK memberikan dampak pada nilai durasi lepas maksimum yang cenderung sama besar terhadap kondisi eksisting.

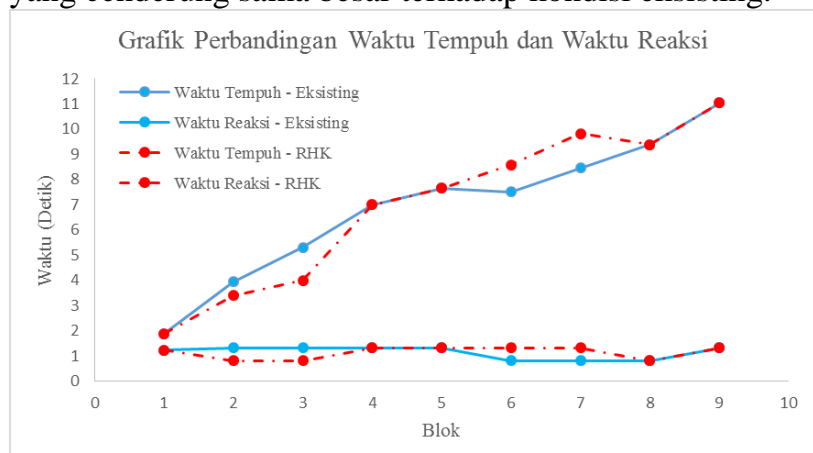

Gambar 12. Grafik Perbandingan Simulasi 2

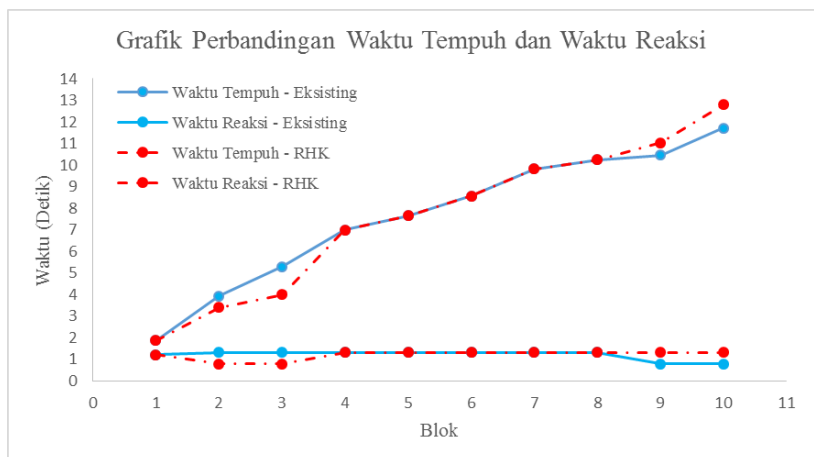

Gambar 13. Grafik Perbandingan Simulasi 3

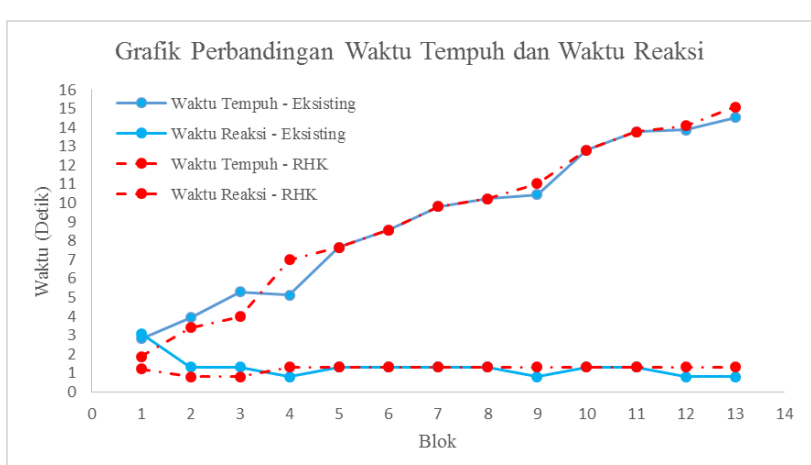

Gambar 14. Grafik Perbandingan Simulasi 11

Berdasarkan tiga grafik yang disajikan penerapan RHK mampu memberikan dampak dalam mengurangi nilai durasi lepas dan durasi tunggu pada tiga blok pertama dimana grafik kondisi RHK berada di bawah grafik kondisi eksisting. Terjadi kenaikan pada grafik kondisi RHK, sedangkan pada grafik kondisi eksisting sebagian terjadi penurunan.

- Kondisi c

Kondisi c adalah kondisi dimana penerapan RHK memberikan dampak pada nilai durasi lepas maksimum yang lebih kecil terhadap kondisi eksisting. Berdasarkan gambar 11 hal ini dapat dilihat pada simulasi 1, 5, 7, 9, 10 , 12, 13, dan 14. Diambil dua simulasi dikarenakan pola yang sama pada hasil kondisi c.

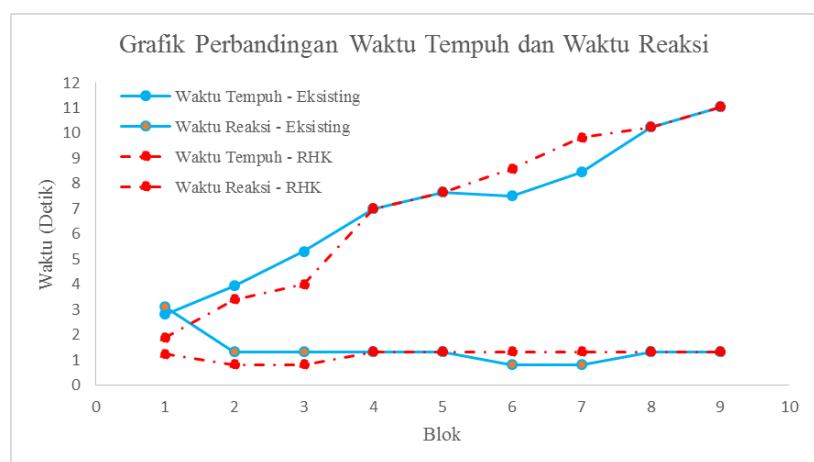

Gambar 15. Grafik Perbandingan Simulasi 7 


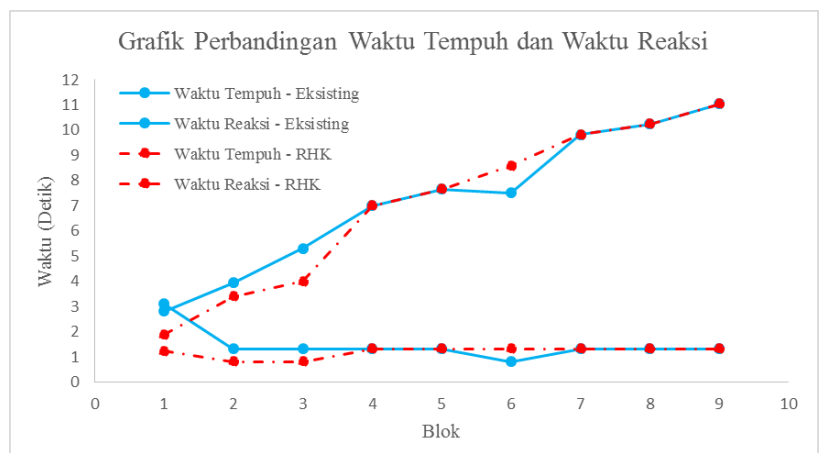

Gambar 16. Grafik Perbandingan Simulasi 9

Berdasarkan dua grafik yang disajikan pada gambar penerapan RHK mampu memberikan dampak dalam mengurangi nilai durasi lepas dan durasi tunggu pada tiga blok pertama dimana grafik kondisi RHK berada di bawah grafik kondisi eksisting. Perbedaan dengan kondisi b, dimana grafik kondisi eksisting pada kondisi c mengalami penurunan yang tidak terlalu besar. Selain itu pada grafik kondisi RHK, tidak adanya penambahan blok akibat penerapan marka RHK.

\section{Pembahasan}

Secara umum pada tiga kondisi kinerja RHK, penerapan RHK berdampak dalam mengurangi durasi tunggu pada keseluruhan hasil simulasi. Berdasarkan gambar 8 grafik durasi tunggu kondisi RHK memiliki pola grafik di bawah grafik kondisi eksisting. Selain itu, dari keseluruhan hasil proses simulasi nyala hijau, grafik kondisi RHK pada tiga blok pertama memiliki nilai Waktu Tempuh dan Waktu Reaksi yang lebih kecil dibandingkan grafik kondisi eksisting. Pengurangan nilai durasi lepas maksimum dan durasi tunggu memberikan pengaruh pada pengurangan nilai tundaan pada antrian kendaraan.

\section{A. Kesimpulan}

\section{RINGKASAN}

Dari hasil survey lapangan dan analisis hasil yang telah dilakukan, diperoleh kesimpulan sebagai berikut :

1. Karakteristik pendekat pada kondisi eksisting adalah sebagai berikut :

a. Karakteristik geometri pada pendekat studi terdiri dari lima lajur. Lajur paling kiri (Lajur 1) adalah lajur belok kiri langsung dengan lebar sebesar 3 meter. Empat lajur yang lain adalah lajur untuk berhenti dengan tiap lajur memiliki lebar sebesar 3,5 meter.

b. Karakteristik arus kendaraan pada pendekat studi untuk sepeda motor sebesar 180 per menit, untuk mobil sebesar 55 per menit, untuk truk sebesar 2 per menit.

c. Karakteristik komposisi kendaraan pada pendekat studi diambil berdasarkan hasil dari simulasi memiliki rasio rata-rata antara sepeda motor dan mobil sebesar 0,83 : 0,17 dengan rata-rata proporsi antrian sepeda motor per lajur sebesar $27,97 \% ; 26,14 \% ; 25,21 \% ; 20,68$.

d. Kinerja persimpangan pada pendekat studi berdasarkan hasil dari proses simulasi memiliki nilai durasi lepas dan durasi tunggu yang cenderung lebih besar sehingga pola grafik kinerja kondisi eksisting sebagian besar diatas pola grafik kondisi RHK.

2. Desain simulasi yang digunakan untuk mencari kinerja pendekat studi dimulai dari simulasi kedatangan kendaraan pada nyala merah, simulasi blok antrian, dan simulasi pelepasan blok antrian pada nyala hijau.

3. Tipe dan dimensi RHK yang digunakan berdasarkan hasil analisis kondisi eksisting adalah RHK tipe kotak dengan panjang RHK sebesar 12 meter. Sehingga dimensi tiap lajurnya sebesar 12 meter x 3,5 meter.

4. Perkiraan kinerja pendekat studi setelah diberlakukan RHK terdiri dari 15 kali hasil proses simulasi yang setara dengan durasi selama satu menghasilkan tiga kondisi kinerja yang terdiri dari kondisi a, kondisi $b$, dan kondisi c. Kondisi a adalah kondisi dimana RHK memberikan nilai tundaan lebih besar terhadap pendekat studi yang diwakili tiga hasil proses simulasi. Kondisi b adalah kondisi dimana RHK memberikan nilai tundaan cenderung sama besar terhadap pendekat studi yang diwakili empat hasil proses simulasi. Kondisi c adalah kondisi dimana RHK memberikan nilai tundaan yang lebih kecil terhadap pendekat studi yang diwakili delapan hasil proses simulasi.

B. Saran

1. Analisis dalam tugas akhir ini memberikan gambaran pengaruh penerapan ruang henti khusus (RHK) untuk sepeda motor pendekat studi sisi utara pada persimpangan Jalan Dr. Ir. H. Soekarno - Jalan Kertajaya Indah ditinjau dari nilai tundaan. Dimana dalam melakukan analisis menggunakan hasil dari proses simulasi terhadap kondisi eksisting dan kondisi RHK. Nilai tundaan yang diambil sebagai acuan parameter kinerja ini menggunakan perbandingan nilai durasi lepas dan durasi tunggu pada keseluruhan antrian.

2. Selain itu, untuk proses analisis selanjutnya disarankan dalam melakukan proses simulasi dapat ditambahkan kendaraan berat dalam antrian.

\section{DAFTAR PUSTAKA}

[1] Hsu Tien Pen, Ahmad Farhan MS, Nguyen Xuan D. 2003. A Comparison Study on Motorcycle Traffic Development in Some Asian Countries-Case Study of Taiwan, Malaysia, and Vietnam. Final Report. The Eastern Asia Society for Transportation Studies (EASTS). Taiwan.

[2] Idris, M., Santoso, Idwan, Tumewu, Willy. 2007. Pengaruh Ruang Henti Khusus Sepeda Motor Terhadap Konflik Lalu Lintas Pada Satu Persimpangan Bersinyal di Kota Bandung. Sistem Teknik Jalan Raya ITB. Bandung.

[3] Wall GT, Davies DG \& Crabtree M. 2003. Capacity Implications of Advanced Stop Lines for Cyclist. TRL Report TRL 585. Transport Research Laboratory. London. 
[4] Shiomi, Yasuhiro., Nishiuchi, Hiroaki. 2011. Evaluation of Spatial Motorcycle Segregation at Isolated Signalized Intersections Considering Traffic Flow Conditions. Paper on Journal of the Eastern Asia Society for Transportation Studies vol 9.

[5] Roess, Roger P., Prassas, Elensa S., McShane, William R. 2004. Traffic Engineering Third Edition. Pearson Education, Inc.

[6] Zukhruf, Febri., Sulaksono, Sony., Frazilla, Russbona. 2009. Kajian Kinerja Ruas dengan Proporsi Arus Sepeda Motor Tinggi Menggunakan Model Microsimulation. Simposium FSTPT XII. Bandung.

[7] Departemen Pekerjaan Umum. Manual Kapasitas Jalan Indonesia (MKJI). Direktorat Jenderal Bina Marga, Jakarta, 1997.

[8] Chu Cong Minh, Kazushi Sano and Shoji Matsumoto. 2005. Characteristics of Passing and Paired Riding Manuevres of Motorcycle. Paper on Journal of The Eastern Asia Society for Transportation Studies vol 6, 186-197. 